\title{
OS LIMITES À FLEXIBILIDADE DA EXECUÇÃO ORÇAMENTÁRIA: A ABERTURA DE CRÉDITOS SUPLEMENTARES PELO ESTADO DE GOIÁS E O CONTROLE REALIZADO PELOS TRIBUNAIS DE CONTAS ${ }^{1}$
}

\section{RESUMO:}

Por meio de pesquisa teórica, analisar-se-á a utilização de instrumentos de flexibilidade orçamentária, especialmente a abertura de créditos suplementares. Na execução orçamentária de Goiás observou-se que são abertos excessivos créditos suplementares, que alteram os valores fixados nas dotações iniciais e demonstram indícios de fragilidade no planejamento e baixa aderência dos gestores às peças orçamentárias, em uma verdadeira desfiguração do orçamento original, dificultando seu acompanhamento e avaliação. $\mathrm{O}$ controle externo realizado pelos Tribunais de Contas possui um grande potencial para contribuir na melhoria da gestão e governança das políticas públicas e recomendar mudanças destinadas a aperfeiçoar à Administração Pública.

PALAVRAS-CHAVE: Orçamento; Flexibilidade orçamentária; créditos suplementares; Estado de Goiás; Tribunal de Contas.

\section{THE LIMITS TO THE FLEXIBILITY OF BUDGET IMPLEMENTATION: THE OPENING OF ADDITIONAL CREDITS BY THE STATE OF GOIAS AND THE CONTROL BY THE AUDIT COURTS}

\begin{abstract}
:
${ }^{1}$ Este artigo faz parte de pesquisa científica desenvolvida junto ao Programa de Pós-graduação de Direito e Políticas Públicas da Universidade Federal de Goiás.

* Doutor em Direito Econômico, Financeiro e Tributário/USP. Professor do PPGDP/UFG. Pesquisador no Projeto Finanças e Políticas Públicas: análises, planejamento e controle no contexto do Federalismo Fiscal cooperativo. Juiz Federal. Endereço postal: Alameda dos Jatobás, quadra 20, lote 06, Jardins Florença, Goiânia. CEP: 74351 018. Endereço eletrônico: leonardobuissa@gmail.com

** Mestranda do Programa de Pós-Graduação em Direito e Políticas Públicas (PPGDP), Nível Mestrado Profissional, da Universidade Federal de Goiás. Especialista em Controle Externo e Governança Pública pelo Instituto Brasiliense de Direito Público - IDP, em Direito Constitucional pela Universidade Cândido Mendes e em Processo Civil pela Faculdade Unida de Campinas -FacUNICAMPS. Analista de controle externo no Tribunal de Contas do Estado de Goiás. Endereço postal: Avenida T- 3, número 1429, apto 1701, CEP 74.210-245, Setor Bueno, Goiânia/GO. Endereço eletrônico: viviabb@hotmail.com
\end{abstract}


Through theoretical research, budgetary flexibility instruments will be analyzed, especially the opening of supplementary credits. In the budgetary execution of Goias, it was observed that excessive supplementary credits were opened, which changes the values fixed in the initial allocations and show signs of weakness in the planning and low adherence of the managers to the pre-fixed budget, disfiguring the original budget, making it difficult to follow up and evaluate. The external control by the Audit Courts has great potential to contribute to improving the management and governance of public policies and to recommend changes aimed at improving the Public Administration.

KEYWORDS: Budget; Budgetary flexibility; additional credits; State of Goias; Audit Courts

\section{INTRODUÇÃO}

O presente artigo objetiva analisar a dimensão que se dá à utilização de instrumentos de flexibilidade orçamentária, especialmente a abertura de créditos suplementares no âmbito do Estado de Goiás. Para tanto, por meio da aplicação de técnicas de pesquisa teórica juntamente com a pesquisa doutrinária será apresentada o legítimo papel do Poder Legislativo e do Poder Executivo no processo orçamentário, com base na construção conceitual do Estado Democrático de Direito e da democracia orçamentária. Ademais, utilizar-se-á o mapeamento normativo sobre o direito financeiro, a fim de identificar os limites jurídicos da flexibilidade da execução orçamentária e os diversos instrumentos pelos quais ela se materializa.

Necessário se faz destacar a relevância do sistema de planejamento governamental por meio das leis orçamentárias, consideradas as mais importantes leis após a Constituição. Assim, o orçamento público consubstancia o principal instrumento para se delinear as prioridades das ações governamentais, eis que é nessa lei de meios que se materializa a fase de formulação das políticas públicas de um determinado período, definindo a quantidade de recursos que cada área de atuação receberá para a efetividade de suas ações, especificamente as que procuram satisfazer as necessidades de cunho social.

É primordial uma maior aproximação entre o que consta no orçamento com os anseios da sociedade, para que este instrumento reflita, efetivamente, de forma democrática e transparente, uma real disposição dos recursos arrecadados pelo Estado. Nesse sentido, em nosso sistema jurídico, as peças orçamentárias são propostas pelos Poderes Executivos de cada ente federativo, que as elaboram e as encaminham ao Legislativo, podendo este aprová-las ou não, e realizar ajustes considerados importantes.

Entretanto, sendo a lei orçamentária uma peça de previsão das receitas e fixação das despesas que ocorrerão no exercício financeiro subsequente, a execução orçamentária necessita 
configurar um contínuo processo de formulação, integração e flexibilização, o que torna compreensível o fato do orçamento executado não corresponder exatamente ao que foi aprovado. Dessa situação decorre a existência de instrumentos de flexibilidade orçamentária, como os créditos adicionais, os quais possuem por objetivo a viabilização das alterações necessárias no decorrer da execução do orçamento.

O ponto central da questão é justamente a dimensão que se dá à utilização desses instrumentos de maleabilidade, eis que subsiste um antagonismo que permeia a utilização dos créditos suplementares, no decorrer da execução orçamentária: por um lado, a abertura dos créditos suplementares possibilitam uma flexibilidade orçamentária no processo de implementação das políticas públicas, ampliando a discricionariedade do agente implementador, e de outro lado comprometem decisões estruturantes tomadas na formulação das políticas públicas.

Existe uma estreita relação entre a eficácia das políticas públicas e a observância dos gestores públicos às peças orçamentárias, no curso de suas execuções. Nessa acepção, ao se falar em implementação de política pública e avaliação da qualidade do gasto público, há de observar a coerência entre o conteúdo dos sucessivos instrumentos de planejamento estatal, que percorre a natureza normativa das leis do plano plurianual, diretrizes orçamentárias e orçamento anual, e a devida execução orçamentária pelos gestores públicos.

Assim, ao compreender no orçamento a primordial atribuição de planejamento das ações governamentais, a atuação do controle de sua execução assume relevante posição em um Estado Democrático de Direito. O controle externo realizado pelos Tribunais de Contas, por meio dos diversos instrumentos de fiscalização, possui um grande potencial para contribuir na melhoria da gestão e governança das políticas públicas e recomendar mudanças destinadas a aperfeiçoar os resultados.

\section{A ORGANIZAÇÃO DAS FINANÇAS PÚBLICAS}

Uma Constituição possui, relativamente ao exercício do poder, dois pontos centrais a serem definidos, o primeiro referente ao titular do poder e o segundo à possibilidade de limites desse poder. No que se refere ao titular do poder, a Constituição Federal brasileira elegeu a democracia, estabelecendo que "todo o poder emana do povo" e, no que tange aos limites, instituiu um Estado Democrático de Direito com poderes harmônicos e independentes e direitos e garantias fundamentais. Nos dizeres de Fábio Konder Comparato (1998), “a democracia 
nunca é o fruto de uma evolução natural e inelutável da sociedade política. Ela se institucionaliza, muito ao contrário, ao longo de um incessante e penoso trabalho de modelagem das instituições políticas, em defesa da dignidade humana."

Percebe-se, assim, que a democracia resulta de um modelo de organização do corpo político, relativa não apenas às estruturas estatais, mas também ao modo como se procedem seus atos decisórios. Na concepção de Marçal Justen Filho (2003, p. 273) a democracia não se limita apenas ao princípio da eletividade para a composição dos órgãos dotados de competências decisórias fundamentais, mas engloba a forma pela qual as decisões são concebidas, e assim descreve:

Trata-se de conceito resultante de características estruturais e funcionais e seu núcleo se relaciona com a existência de (a) mandatos eletivos temporários para os cargos políticos de maior relevância e de (b) instrumentos de garantia e controle do exercício do poder, destinados a assegurar tanto a referibilidade das decisões à vontade popular como a realização dos princípios e valores fundamentais. Essa organização do poder político estatal deve assegurar a limitação interna das competências, de modo a evitar a possibilidade de decisões arbitrárias ou resultantes de preferências subjetivas irracionais dos eventuais e temporários ocupantes de cargos e funções públicas.

Nessa acepção, em um Estado Democrático de Direito, ante a premissa de se preservar processos decisórios democraticamente, o poder financeiro se reconhece como o próprio poder do Estado, de acordo com sua atividade e limitações. Torna-se, assim, indispensável o acolhimento dos direitos como matéria de finanças públicas, conquanto são instrumentos financiados coletivamente com o intuito de se promover o bem estar social. No mesmo sentido são as palavras de Paulo Otero (2003) “a limitação do poder e a própria separação dos poderes surgem como instrumentos tendentes a garantir ou assegurar um objetivo nuclear: a liberdade dos cidadãos."

Ademais, a existência de necessidades materiais acarreta a previsão de direitos na Constituição, especialmente os de cunho social e a realização desses direitos constitui o fim precípuo do Estado que, para tanto, arrecada recursos da coletividade. Entretanto, como a demanda é volumosa e os recursos são limitados, as necessidades precisam ser organizadas e priorizadas.

Por conseguinte, a efetividade da atuação estatal na concretização dos direitos é materializada por meio de um instrumento legal de planejamento que estabelece as prioridades e direciona as ações governamentais, o orçamento público. Nesse sentido, a garantia da fruição dos direitos tidos como fundamentais pelos cidadãos requer uma agenda política planejada e 
ordenada nas peças orçamentárias, com a previsão dos gastos públicos e a respectiva alocação dos recursos no orçamento.

O orçamento reflete o plano de ação do governo, que, segundo Kiyoshi Harada (2006) sempre será elaborado com base em uma decisão política. Com isso, "parlamentares ligados à massa pleiteiam inclusão de despesas nos setores que a ela interessam: gastos e normas com a saúde, educação, a assistência social, a habitação popular etc.” (HARADA, 2006).

$\mathrm{Na}$ democracia brasileira, o orçamento público consiste em um instrumento legal por meio do qual os cidadãos, através dos seus representantes eleitos para o Parlamento, preveem as receitas e fixam as despesas que podem ser realizadas pelo Poder Executivo, estabelecendo as prioridades e direcionando as ações governamentais. Assim, no Estado Democrático de Direito brasileiro as competências orçamentárias se dividem entre os Poderes Legislativo e Executivo, de tal forma que o orçamento público é o resultado da atuação harmônica e equilibrada desses Poderes.

Há de se ressaltar que nos dias atuais o orçamento não constitui mais um "papel em branco" para a livre disposição e distribuição dos recursos orçamentários, eis que um grande volume desses recursos já possui uma vinculação previamente determinada em âmbito constitucional ou legal. Desse modo, conforme expõe Gabriel Lochagin (2016) "se o emprego dos recursos por meio do orçamento público, por um lado, exerce influência determinante sobre a atividade estatal, haveria certo excesso em qualificar o orçamento público como a expressão absoluta do programa político de ação do governo".

O ordenamento jurídico pátrio confere ao Poder Legislativo, nesse aspecto, a função precípua para o exercício do Estado Democrático de Direito, eis que as diretrizes e objetivos das políticas públicas são opções políticas que cabem aos representantes do povo e, portanto, ao Poder Legislativo, que as concretizam sob a forma de leis, para então o Poder Executivo poder executá-las, de acordo com a clássica separação das funções estatais.

Nesse ponto cabe ressaltar o diagnóstico realizado por Marçal Justen Filho (2003), que utilizando-se dos ensinamentos de Chavallier, alertou sobre o cenário de "crise" para os sistemas democráticos ocidentais, a qual se deriva de "quatro fatores principais: a crise da representatividade, a crise da participação, a crise da cidadania e a perda de referência”. E assim afirma:

A legitimidade dos representantes não é então adquirida pela simples magia da eleição: a democracia não se reduzirá nunca apenas aos processos eletivos; ela supõe ainda ao respeito ao pluralismo, a 
garantia dos direitos e liberdades, o debate sobre as escolhas coletivas... Em outras palavras, a legitimidade dos representantes depende de sua conformidade com certas exigências de ordem ética.

Nesse mesmo sentido, Natasha Salinas (2013) descreve que "a crise da democracia representativa é atribuída às limitações dos arranjos institucionais que estruturam a forma como o Poder Legislativo, o Presidente da República, bem como grupos de interesse diversos relacionam-se entre si para a formulação de políticas públicas legisladas". Consequentemente, ante a descrença em acreditar que as leis que surgem do processo legislativo refletem as reais necessidade sociais, percebe-se, atualmente, um gradual desrespeito pelo papel da lei enquanto elemento estruturador das ações da Administração Pública.

Entretanto, o reconhecimento das problemáticas envolvendo o processo de produção legislativa não pode ser utilizado como subterfúgio para a desobediência às finalidades e implicações dos instrumentos legais. Assim, no Brasil, o orçamento é lei aprovada pelo Poder Legislativo, o qual tem início com o projeto formulado pelo Poder Executivo, é discutido, submetido a emendas e pareceres de comissão e vai para aprovação final, sanção, promulgação e publicação. Referido trâmite necessita assegurar à lei orçamentária ser expressão da vontade popular, característica essa que identifica o orçamento como lei material em sua substância.

\section{A FLEXIBILIDADE DA EXECUÇÃO ORÇAMENTÁRIA E SEUS LIMITES JURÍDICOS}

Em nosso ordenamento jurídico, a noção básica de equilíbrio orçamentário pressupõe que no orçamento anual o total das despesas fixadas seja similar ao das receitas previstas. À primeira vista, referida afirmação pode parecer simples, mas, pelo contrário, trata-se de um tema de extrema complexidade, tendo seu maior expoente a Lei de Responsabilidade Fiscal, legislação concebida em prol do equilíbrio fiscal.

No decorrer da elaboração e aprovação dos orçamentos, e infelizmente esta tem sido uma prática recorrente na Administração pública brasileira, o equilíbrio fiscal pode ser artificialmente manipulado pela negligente previsão "otimista" de arrecadação, por subestimativa de despesas ou até mesmo pela combinação de ambas práticas, em absoluto desrespeito aos basilares princípios do processo orçamentário (OLIVEIRA, 2015).

Doris de Miranda Coutinho (2018) assevera que a superestimação das receitas previstas nos projetos orçamentários consiste em uma realidade que corrobora para o irrealismo orçamentário. Dessa forma, dois problemas podem surgir: o primeiro relacionado ao 
desequilíbrio na execução orçamentaria, eis que se gasta mais do que se arrecada; e o segundo é o fato do Poder Executivo possuir uma extensa margem de remanejamento para realizar anulações de dotações orçamentárias como fontes de recursos para a abertura dos créditos suplementares.

Entretanto, não se pode negar que a ausência de veracidade das estimativas das receitas e despesas podem também derivar de impropriedades técnicas, decorrentes de complexidades econômicas e organizacionais dos entes federativos, eis que as margens de erro são maiores quando não há a disponibilização de técnicas mais apuradas de previsão e controles tecnologicamente avançado das despesas (OLIVEIRA, 2015). Assim, como nem sempre as previsões podem compreender as demandas existentes à época da execução, o direito orçamentário oferece mecanismos de reajustamento nas programações orçamentárias no decorrer de sua execução, os denominados mecanismos de flexibilidade do orçamento.

Por conseguinte, o lapso temporal existente entre o período da elaboração do orçamento e sua efetiva execução, a ausência de adequado planejamento, a modificação nas prioridades das políticas públicas ou as alterações financeiras de mercado dos bens e serviços, são exemplos de situações que exigem do Poder Público ajustes na programação financeira. Por meio de expressa previsão constitucional e legal, foram criados flexíveis instrumentos de gestão para abranger situações que não foram abarcadas na elaboração da proposta orçamentária, mas que devem ser incluídos no orçamento do exercício, os denominados créditos adicionais, sendo no mesmo sentido os ensinamentos de Régis de Oliveira (2008):

A decisão de alocação das prioridades de despesas, ao lado das finalidades encampadas no ordenamento normativo, pode sofrer flutuações, ao longo da execução orçamentária. É que a mutação das situações, a alteração das conveniências mundiais, a mudança de interesses pode ocorrer durante o exercício financeiro. A realidade fática é mutável empiricamente. A previsão do homem é limitada. Podem surgir situações emergenciais ou, mesmo, a falta de uma adequada alocação de recursos. Tudo a impor alterações ao longo da execução do orçamento. Isso leva a uma contingência não prevista, o que obriga a alteração do gasto. Por isso é que há a previsão dos créditos adicionais.

Dessa forma, para que sejam modificados os limites de despesas da Lei Orçamentária Anual são utilizados os créditos orçamentários adicionais, que conforme definição do art. 40 da Lei ${ }^{\circ} 4.320 / 64$, são autorizações de despesa não computadas ou insuficientemente dotadas na lei do orçamento. Conforme o art. 41 de referida lei, os créditos adicionais classificam-se em: suplementares, os destinados a reforço de dotação orçamentária; especiais, os destinados a despesas para as quais não haja dotação orçamentária específica; e extraordinários, os 
destinados a despesas urgentes e imprevistas, em caso de guerra, comoção interna ou calamidade pública.

A questão da flexibilidade orçamentária perpassa pelo sensível ponto do equilíbrio de poderes, especificamente entre o Legislativo e o Executivo, os quais possuem definidas atribuições em matéria orçamentária. Desse modo, alterar o orçamento significa modificar um instrumento legal que estabelece políticas públicas e tal modificação não pode ser realizada sem o crivo do Poder Legislativo.

Ademais, a flexibilidade não significa ampla possibilidade de alteração da lei orçamentária, pelo contrário, são poderes conferidos para assegurar o cumprimento dos fins da própria lei, estando balizada pelos delineamentos legais que a lei orçamentária definiu em seu texto normativo. Até porque, um sistema de execução orçamentária largamente flexível debilita os controles que podem ser exercidos sobre a conduta dos agentes encarregados de orientar a concretização dos gastos públicos.

Tais considerações demonstram que a necessária coerência entre o conteúdo dos sucessivos instrumentos de planejamento estatal, que percorre a natureza normativa das leis do plano plurianual, diretrizes orçamentárias e orçamento anual, e a devida execução orçamentária pelos gestores públicos tem a finalidade de se coibir o surgimento de orçamentos paralelos, que não coadunam com o contexto de planejamento prévio e à decisiva manifestação da vontade legislativa.

\section{A ABERTURA DOS CRÉDITOS SUPLEMENTARES NO ESTADO DE GOIÁS}

A maioria das referências históricas dos créditos adicionais costumam ser bastante criticadas, já que em virtude do excesso em sua utilização, referidos instrumentos de flexibilidade orçamentária foram e ainda são considerados como adversários do equilíbrio orçamentário. Conforme já explanado, há três tipos de créditos adicionais: os especiais, extraordinários e os suplementares. Os créditos suplementares são aqueles abertos para reforço de dotações orçamentárias que, no decorrer de sua execução, se demonstraram insuficientes, desse modo, a abertura de créditos suplementares significa a prévia existência de programas dispostos na lei orçamentária anual, entretanto, por algum motivo, tal crédito constante não foi suficiente para atender à despesa demandada.

O caput do art. 43 da Lei $n^{\circ} 4.320 / 64$ estabelece que a abertura de créditos suplementares depende da existência de recursos disponíveis. Por conseguinte, de acordo os 
incisos do referido art. $43, \S 1^{\circ}$, os recursos que cobrirão os créditos são: o superávit financeiro apurado em balanço patrimonial do exercício anterior; os provenientes de excesso de arrecadação, os resultantes de anulação parcial ou total de dotações orçamentárias ou de créditos adicionais autorizados em lei; o produto de operações de crédito autorizadas, em forma que juridicamente possibilite ao Poder Executivo realizá-las.

A abertura dos créditos suplementares depende de prévia autorização legislativa, assim, para dar dinamismo à execução orçamentária e evitar sucessivos pedidos de suplementação ao Poder Legislativo, o art. 165, $\S 8^{\circ}$ da Constituição, dispõe que a lei orçamentária anual não conterá dispositivo estranho à previsão da receita e à fixação da despesa, não se incluindo na proibição a autorização para a abertura de créditos suplementares.

Gabriel Lochagin (2016) leciona que o comando do art. $165, \S 8^{\circ}$ da Constituição repetiu, sem alteração do texto, preceito que sistematicamente tem feito parte das constituições brasileiras desde a Reforma Constitucional de 1926, que acrescentou $\S 1^{\circ}$ ao art. 34 da Constituição de 1891, afirmando que:

Essa reforma destinava-se a eliminar as chamadas caudas orçamentárias, afirmando o princípio da
exclusividade de modo a evitar que dispositivos sem conteúdo orçamentário fossem inclú́dos na lei
de orçamento. Disso se extrai a existência de um conceito constitucional de matéria orçamentária
(isto é, matéria própria da lei de orçamento), que, no seu sentido constitucional, apenas pode ser a
previsão de receitas e a fixação de despesa. A vedação, entretanto, não é absoluta e o texto
constitucional previu duas exceções: além da matéria orçamentária propriamente dita, a lei
orçamentária poderá conter autorização prévia para a abertura de créditos suplementares,
comumente denominada de margem de remanejamento, e a autorização para contratação de
operações de crédito.

Com base nessa autorização constitucional, o art.7 ${ }^{\circ}$, inciso I da Lei $n^{\circ} 4.320 / 64$, estabeleceu que a lei orçamentária poderá conter autorização ao Executivo para abrir créditos suplementares até determinada importância, que costuma ser um percentual da despesa autorizada no orçamento, sendo esta uma exceção ao princípio da exclusividade. A relevância desse permissivo legal, também denominado de margem de remanejamento, pode ser demonstrada pela importância cada vez maior que as leis orçamentárias concedem para este tema, aumentando cada vez mais os limites de sua aplicação, o que acentua a institucionalização dessa prática na política orçamentária brasileira.

Por consequência, ao longo dos anos, o Estado de Goiás vem dispondo em suas leis orçamentárias anuais a abertura de créditos suplementares pelo Poder Executivo até o limite de $25 \%$ sobre o total da despesa nela fixada, limite este estabelecido no artigo $9^{\circ}$ das LOAS do Estado de Goiás, com exceção do exercício de 2019 que fixou o limite em $30 \%$. 
Infelizmente, as sucessivas leis orçamentárias anuais do Estado de Goiás excluem deste limite de $25 \%$, os créditos adicionais que possuam como indicação de recursos os resultantes de anulação de valor alocado na Reserva de Contingência, o excesso de arrecadação da receita, superávit financeiro, ajustamento de Grupos de Despesa em um mesmo órgão sem alteração do total da categoria econômica, repasse de recursos financeiros mediante transferências financeiras, bem como os créditos suplementares destinados a suprir insuficiência nos grupos de despesas com pessoal e encargos sociais. Essas situações excluídas do limite de $25 \%$ costumam estar dispostas no artigo 10 das LOAS do Estado de Goiás.

Os casos excluídos do limite de $25 \%$ apenas não abrangem as operações de crédito dos recursos previstos no $\S 1^{\circ}$, art. 43 da Lei $n^{\circ} 4.320 / 64$. Percebe-se, assim, que as exceções ao limite de $25 \%$ englobam, praticamente, todas as possibilidades para abertura de créditos suplementares, ou seja, referidas exceções suprimem o limite de $25 \%$ estabelecido pela lei orçamentária, tornando-o quase inexistente.

Em uma breve análise da execução orçamentária do Estado de Goiás, verifica-se que, para o exercício de 2019, o governo do Estado de Goiás emitiu 438 atos normativos para abertura de créditos adicionais no valor total de $\mathrm{R} \$ 10.684 .040 .046,33$ (dez bilhões, seiscentos e oitenta e quatro milhões, quarenta mil, quarenta e seis reais e trinta e três centavos), representando 32,70\% da despesa fixada na LOA - Lei estadual $n^{\circ} 20.419 / 2019$. Desse valor, 97,99\% referem-se à créditos suplementares; 48,29\% dos créditos utilizaram como origem de recurso a Reserva de Contingência; 42,25\% utilizaram Anulação de Dotação, previstas no inciso IV, $\S 1^{\circ}$, art. 43 da Lei $\mathrm{n}^{\circ} 4.320 / 64$; e 55,78\% dos créditos foram para cobrir gastos do grupo Pessoal e Encargos Sociais.

A princípio, os créditos suplementares deveriam ser usados de forma excepcional, uma vez que são mecanismos retificadores de um orçamento planejado. Entretanto, percebe-se que o Poder Executivo do Estado de Goiás tem exagerado no seu uso, de forma que a abertura excessiva de créditos suplementares tem causado desequilíbrios na execução orçamentária. $\mathrm{O}$ inciso I, art. $7^{\circ}$ da Lei 4.320/64, deve ser interpretado com prudência e em consonância com o inciso VII, art. 112 da Constituição Estadual, o qual veda a concessão ou utilização de créditos ilimitados.

A “técnica orçamentária” adotada no Estado de Goiás, além de contrariar o disposto neste comando constitucional, provoca a operacionalização do orçamento pelo Poder Executivo sem o crivo do Poder Legislativo, o que vai de encontro ao inciso V e VI, art. 112 da 
Constituição Estadual. As substanciais alterações nos valores inicialmente fixados nas dotações orçamentárias demonstram deficiências e fragilidade no sistema de planejamento e a baixa aderência dos gestores públicos às peças orçamentárias, bem como dificultam seu devido acompanhamento e avaliação.

A despeito do citado dinamismo e necessários ajustes orçamentários proporcionados pelos créditos suplementares é indispensável que sua utilização seja realizada de forma planejada em virtude da possibilidade de o seu uso abusivo descaracterizar e desvirtuar o orçamento original. Neste viés, com a abertura dos créditos suplementares, embora os gestores públicos possam adaptar as políticas públicas de acordo com as condições específicas deparadas com o contexto, por outro lado, eles não possuem a legitimidade democrática para tomar decisões alocativas sem a efetiva participação do Poder Legislativo.

Deve-se sempre ter em mente que o processo legislativo de abertura de crédito suplementar não configura uma ampliação ou prorrogação do processo de elaboração do orçamento, eis que essa fase já foi concluída, conforme os prazos estabelecidos na Constituição Federal. Gabriel Lochagin (2016) aduz que a peculiaridade na aprovação dos créditos suplementares está presente na fase de execução orçamentária, fase esta que o Poder Legislativo necessita participar, e assim prossegue "conquanto a decisão parlamentar não seja de execução da despesa em si, mas de autorização para execução de determinada dotação acima dos montantes anteriormente previstos, trata-se de uma participação constitucionalmente indispensável."

\section{A ATUAÇÃO DOS TRIBUNAIS DE CONTAS E PROPOSTAS DE MELHORIA NOS MECANISMOS DE FLEXIBILIDADE ORÇAMENTÁRIA}

O estado constitucional se baseia no controle do poder da lei. É impossível a existência de um estado constitucional sem mecanismos que controlem o cumprimento da lei pelo Estado, inclusive no que tange ao gasto público. O estado social, forma em que a maioria dos estados do mundo desenvolvido são constituídos, articula grande parte de sua atividade em torno do gasto público. Portanto, é muito difícil imaginar atualmente o exercício do poder público em um marco constitucional sem a existência de um sistema consistente de controle de gastos públicos.

Esse controle, por sua vez, não deve apenas examinar as despesas e os recursos em formato numérico e contábil, mas também assegurar que as despesas realizadas atendam ao 
objetivo e destino para o qual o Legislativo os autorizou através da aprovação da lei orçamentária. Daí a enorme importância da atividade fiscalizatória realizada pelos órgãos de controle externo no Estado democrático, uma vez que eles não exercem simplesmente uma função de auditoria ou de contabilidade, secundária à administração financeira do Estado, mas uma fiscalização da gestão pública, atendendo critérios de economia, eficácia e eficiência (VIVES, 2003).

O Tribunal de Contas auxilia o Poder Legislativo no controle externo. Possui competência para a fiscalização de quaisquer entidades públicas, incluindo as contas dos Poderes Executivo, Legislativo, Judiciário e do Ministério Público, fiscalizando, também, as entidades privadas que utilizem dinheiro público para a execução de suas atividades.

No ordenamento jurídico brasileiro há a previsão de Tribunal de Contas no âmbito federal e estadual, assim como a possibilidade de criação, como órgão estadual, de Tribunal de Contas dos Municípios. Com efeito, o art. 71 da Constituição Federal prevê que o controle externo será exercido com o auxílio do Tribunal de Contas da União, competência que o faz atuar na fiscalização contábil, financeira, orçamentária, operacional e patrimonial da União e das entidades da administração direta e indireta, quanto à legalidade, legitimidade, economicidade, aplicação das subvenções e renúncia de receitas.

As Cortes de Contas fiscalizam as entidades e órgãos da Administração Pública por meio de auditorias e inspeções, podendo expedir medidas cautelares para impedir futura lesão ao erário e garantir o cumprimento de suas decisões. Por sua vez, a competência sancionatória dos Tribunais de Contas consiste na aplicação de sanções por ilegalidades de despesas ou irregularidade de contas.

Tanto pela sua importância na avaliação do desempenho governamental na implementação e execução das políticas públicas, tanto para fins de alimentação do processo de planejamento, o acompanhamento da execução orçamentária consiste em uma das principais atribuições do controle externo. Dentro desse panorama, ao observar que a pouca adesão e observância às peças orçamentárias são obstáculos inerentes para o efetivo êxito das políticas públicas, o controle da execução orçamentária pelos Tribunais de Contas assume posição de destaque em nossa democracia.

Nesse sentido, o Tribunal de Contas, na atuação de sua competência, não deve apenas se limitar a indicar os problemas por meio de um controle de legalidade, mas necessita agir em parceria com os gestores públicos, recomendando as medidas capazes de melhorar a qualidade 
dos gastos e dos serviços públicos. Assim, as Cortes de Contas devem utilizar de sua competência para afastar os erros e desvirtuamentos da atuação estatal, encorajando a Administração Pública a utilizar-se de boas práticas de governanças que potencialize a qualidade do gasto público, intervindo, assim, para a concretização qualitativa dos direitos sociais.

O controle da execução orçamentária pelos Tribunais de Contas deve ser realizado conforme as proposições defendidas por Ulisses Jacoby (2016), o qual, costumeiramente, demonstra a progressão de análise do controle externo, a partir de um exame meramente de conformidade contábil-legal para a incorporação de aspectos qualitativos na aferição da eficiência e da legitimidade dos gastos públicos. Por tal razão, é que o autor postula que o controle da execução orçamentária, no âmbito do controle externo, opera como mecanismo que retroalimenta o planejamento e as ações governamentais voltadas para a implementação das políticas públicas, promovendo a correção e a repressão de desvios e incentivando boas práticas de governança.

Na prática, e isso restou cabalmente demonstrado no Estado de Goiás, observa-se que os gestores acabam se aproveitando das imprecisas estimativas de receitas, aliadas às modificações que ocorrem no momento da execução do orçamento, para aumentarem os limites e extensões de instrumentos que permitem maior flexibilidade orçamentária. Nesse sentido, para uma boa condução das finanças públicas, vê-se como oportuno e atual a atuação do Tribunal de Contas do Estado de Goiás, o qual deveria oficiar o Governador do Estado bem como os Secretários da Fazenda e do Planejamento para que estes elaborem e encaminhem à Assembleia Legislativa projeto de lei orçamentária com percentual definido para abertura de créditos suplementares. As situações excluídas do limite devem ter lei de autorização diversa para que o Poder Legislativo possa ter conhecimento e controle sobre a aplicação dos recursos públicos.

Ademais, poderia haver um estudo realizado no âmbito do controle externo para a possibilidade de se impor legalmente o bloqueio de pedidos de abertura de créditos suplementares para dotações que já tiverem pedido de reduções. Com tal imposição legal, a Administração Pública necessitaria de um maior comprometimento com o planejamento orçamentário.

Diante de tais observações, percebe-se que a utilização dos instrumentos de flexibilidade orçamentária, especificamente os créditos suplementares, podem ser melhores 
utilizados pelos gestores públicos a partir da reflexão sobre sua finalidade e uma postura assertiva dos órgãos de controle externo, especialmente os Tribunais de Contas, de maneira que o processo de execução orçamentária fique menos permeável à influência de interesses políticos e à ocorrência de fraudes. Assim, não cabe às Corte de Contas somente verificar o cumprimento das disposições legais, mas sim realizar uma análise embasada em técnicas orçamentárias e de gestão, firmando compromisso com o planejamento e o equilíbrio orçamentário.

\section{CONCLUSÃO}

Sob a perspectiva democrática, o orçamento público aprovado pelo Parlamento consiste no compromisso do Estado com os cidadãos sobre a realização dos serviços públicos eleitos como prioritários para os atendimentos das necessidades sociais, nas medidas e extensões estipuladas no planejamento. Para o atendimento desses objetivos, existem os créditos orçamentários. Nesse sentido, a indispensável aprovação desses créditos pelo Poder Legislativo não pode significar que referido poder, o qual representa o povo, apenas tome conhecimento das políticas acolhidas, mas sim que delas participem, fazendo parte do processo decisório.

Referido compromisso, consubstanciado nas leis orçamentárias, reputa-se jurídico e democraticamente exigível. Entretanto, percebe-se que os instrumentos de flexibilidade orçamentária demonstram ser indispensáveis para a atuação estatal diante das diversas alterações da realidade, sendo que sem elas a lei orçamentária se tornaria uma peça obsoleta a assegurar os próprios fins a que objetiva.

Ademais, orçamentos incompletos ou inexatos são extremamente prejudiciais e possuem como principais causas a superestimava de receitas. Desse modo, além de ser uma lamentável realidade que contribui para o irrealismo orçamentário, a prática de se superestimar as receitas previstas nas propostas orçamentárias ocasionam dois grandes problemas: o primeiro relacionado ao desequilíbrio na execução orçamentária, eis que se gasta mais do que se arrecada, e o segundo consiste no fato de o Poder Executivo ter uma vasta margem para realizar anulação de dotações orçamentárias como fonte de recursos para a abertura de créditos suplementares, de modo que, quanto maior a receita estimada, maior será a margem para a solicitação de abertura de referidos créditos no exercício financeiro.

A maleabilidade orçamentária, por meio da utilização dos créditos suplementares, apenas deve ser possível se os limites da autorização previstos na lei orçamentária foram 
respeitados. Nesse sentido, cabe ao Poder Legislativo a competência exclusiva de estabelecer os limites e as condições do emprego das margens de remanejamento.

Na execução orçamentária do Estado de Goiás observou-se que são abertos excessivos créditos suplementares, que alteram, substancialmente, os valores fixados nas dotações iniciais e demonstram indícios de fragilidade no planejamento e baixa aderência dos gestores públicos às peças orçamentárias, em uma verdadeira desfiguração do orçamento original, o que dificulta seu devido acompanhamento e avaliação

O controle externo realizado pelos Tribunais de Contas, por meio dos diversos instrumentos de fiscalização, possui um grande potencial para contribuir na melhoria da gestão e governança das políticas públicas e recomendar mudanças destinadas a aperfeiçoar as atividades orçamentárias dos órgãos e entidades pertencentes à Administração Pública, na medida em que a fiscalização tempestiva e assertiva pode ocasionar a aderência ao planejamento e equilíbrio orçamentário e respeito à sistemática constitucional das atribuições parlamentares no orçamento público.

\section{REFERÊNCIAS}

BRASIL. Constituição da República Federativa do Brasil de 1988. Diário Oficial da União. Brasília, DF, 5 out. 1988.

Lei $n^{\circ}$ 4.320, de 17 de março de 1964. Diário Oficial da República Federativa do Brasil. Brasília, DF, 17 mar. 1964.

Lei Complementar $n^{\circ}$ 101, de 4 de maio de 2000. Diário Oficial da República Federativa do Brasil. Brasília, DF, 04 maio. 2000.

18 fev. 2019.

Lei estadual $n^{0}$ 20.419, de 18 de fevereiro de 2019. Diário Oficial do Estado de Goiás,

ALEXY, Robert. Teoria dos Direitos Fundamentais (teoria e direito público). Tradução Virgílio Afonso da Silva. $2^{a}$ ed. São Paulo: Malheiros, 2015.

BLIACHERIENE. Ana Carla. Controle da Eficiência do Gasto Orçamentário. Belo Horizonte: Fórum, 2016.

BUCCI, Maria Paula Dallari. Políticas Públicas: reflexões sobre o conceito jurídico. São Paulo: Saraiva, 2006. 
CANOTILHO. J. J. Gomes. Direito Constitucional e Teoria da Constituição. $7^{\mathrm{a}}$ ed. Coimbra: Edições Almedina, 2004.

CANOTILHO, José Joaquim Gomes. A Lei do Orçamento. In Estudos em Homenagem ao Prof. Doutor J.J. Tixeira Ribeiro. Universidade de Coimbra: Boletim da Faculdade de Direito, Número Especial, 1979, p. 556.

COMPARATO, Fábio Konder. Ensaio sobre o juízo de constitucionalidade de políticas públicas. Revista de Informação Legislativa, Brasília, ano 35, n. 138, abr./jun. 1998.

CONTI, José Maurício. Levando o Direito Financeiro a sério: a luta continua. $2^{\mathrm{a}}$ ed. São Paulo: Blucher. 2018.

COUTINHO, Doris de Miranda. Finanças Públicas: Travessia entre o passado e o futuro. São Paulo: Blucher. 2018.

DI PIETRO, Maria Sylvia Zanella. Direito Administrativo. 30ª ed. São Paulo: Atlas, 2017.

GIACOMONI, James. Orçamento Público. 17ª ed. São Paulo: Atlas. 2017.

HARADA, Kiyoshi. Direito Financeiro e Tributário.15. ed. São Paulo: Atlas. 2006.

JACOBY, Jorge Ulisses. Tribunais de Contas do Brasil: jurisdição e competência. $4^{\mathrm{a}}$ ed. Belo Horizonte: Fórum, 2016.

JUSTEN FILHO, Marçal. Agências Reguladoras e Democracia: existe um Déficit Democrático na "Regulação Independente"?. Revista de Direito Público da Economia - RDPE, Belo Horizonte, ano 1, n. 2, p. 273-301, abr./jun. 2003

LIMA, Luiz Henrique; OLIVEIRA, Weder de; CAMARGO, João Batista. Contas Governamentais e Responsabilidade Fiscal: desafios para o controle externo - estudo de Ministros e Conselheiros Substitutos dos Tribunais de Contas. Belo Horizonte: Fórum, 2017.

LABAND, Paul apud FARIA, Rodrigo de Oliveira. Natureza Jurídica do Orçamento e Flexibilidade Orçamentária. Dissertação (Mestrado em Direito) Faculdade de Direito da Universidade de São Paulo. São Paulo, 2009.

LOCHAGIN, Gabriel Loretto. A execução do orçamento público: flexibilidade e orçamento impositivo. São Paulo: Blucher. 2016.

LOTTA. Gabriel. Spanghero. Implementação de políticas públicas: o impacto dos fatores relacionais e organizacionais sobre a atuação dos burocratas de nível de rua no Programa Saúde da Família. 2010. Tese (Doutorado) - Universidade de São Paulo, Departamento de Ciência Política, São Paulo.

OLIVEIRA, Weder de. Curso de Responsabilidade Fiscal/Direito, Orçamento e Finanças Públicas. Vol. I. $2^{a}$ edição. Belo Horizonte: Fórum, 2015. 
OLIVEIRA. Régis Fernandes de. Curso de Direito Financeiro. $2^{\mathrm{a}}$ ed. São Paulo: Revista dos Tribunais, 2008.

OTERO, Paulo. Legalidade e administração pública: o sentido da vinculação administrativa à juridicidade. Coimbra: Almedina, 2003.

PINHEIRO, Luís Felipe Valerim. Políticas Públicas nas Leis Orçamentárias. São Paulo: Saraiva, 2015.

PINTO, Élida Graziane. Financiamento dos direitos à saúde e à educação: uma perspectiva constitucional. $1^{\text {a }}$ reimpressão. Belo Horizonte: Fórum, 2017.

SALINAS, Natasha Schmitt Caccia. Avaliação legislativa no Brasil: apontamentos para uma nova agenda de pesquisa sobre o modo de produção das leis. Brasília: Revista Brasileira de Políticas Públicas, vol. 3, n2, jul-dez 2013.

SARLET, Ingo Wolfgang. A eficácia dos Direitos Fundamentais: uma teoria geral dos direitos fundamentais na perspectiva constitucional. $12^{\mathrm{a}}$ ed. Porto Alegre: Livraria do Advogado, 2015.

VIVES, Francesc Vallès: El control externo del gasto público - Configuración y garantia constitucional. Madrid, 2003. 